\title{
EL PENSAMIENTO SISTÉMICO Y SUS RELACIONES CON EL ÁMBITO EDUCATIVO: DEL PARADIGMA LINEAL A LA TRAMA CIRCULAR
}

LEANDRO ARBEY GIRALDO HENAO

Universidad Tecnológica de Pereira 


\title{
EL PENSAMIENTO SISTÉMICO Y SUS RELACIONES CON EL ÁMBITO EDUCATIVO: DEL PARADIGMA LINEAL A LA TRAMA CIRCULAR*
}

\begin{abstract}
Resumen: el presente artículo reflexiona sobre el sentido de los diálogos entre educación, comunicación y cultura, a partir de las tesis planteada por Fritjof Capra (1998) en su teoría de los sistemas, según la cual es necesaria una nueva comprensión científica de la vida en todos los niveles de los sistemas vivientes: organismos, sistemas sociales y ecosistemas. Capra aborda la importancia de aquellos desde el pensamiento sistémico que sustentan ideas de conexión, totalidad y relación puestas en circulación en las reflexiones contemporáneas. Se ponen en discusión para el olvido del paradigma lineal y la comprensión de la trama circular del hombre y sus fenómenos de estudio.
\end{abstract}

Palabras clave: educación, pensamiento sistémico, cultura, comprensión circular, hibridez.

\section{THE SYSTEMIC THINKING AND ITS RELATIONS WITH THE EDUCATIONAL FIELD:FROM LINEAR PARADIGM TO CIRCULAR WEFT}

\begin{abstract}
This article reflects on the meaning of the dialogue between education, communication and culture, based on the arguments raised by Fritjof Capra (1998) in his theory of systems, according to which a new scientific understanding of life in all levels of living systems: organisms, social systems and ecosystems is necessary. Capra addresses the importance of such systems from the systemic thinking; systems that support connection, entirety and relationship ideas all current in contemporary reflections. They are discussed in order to forget about the linear paradigm and understand the circular plot of man and his objects of study.
\end{abstract}

Keywords: education, systemic thinking, culture, understanding circular, hybridity.

Fecha de recepción: Junio 1 de 2015

Fecha de aceptación: Agosto 31 de 2015

Forma de citar (APA): Giraldo, L. (2016). El pensamiento sistémico y sus relaciones con el ámbito educativo: del paradigma lineal a la trama circular. Revista Filosofía UIS, 15 (1), 279-312, doi: http://dx.doi.org/10.18273/revfil.v15n1-2016014

Forma de citar (Harvard): ): Giraldo, L. (2016). El pensamiento sistémico y sus relaciones con el ámbito educativo: del paradigma lineal a la trama circular. Revista Filosofía UIS, 15 (1), 279-312.

Leandro Arbey Giraldo Henao: colombiano. Doctorando en Ciencias de la educación, Universidad Tecnológica de Pereira. Licenciado en español y comunicación Audiovisual, Magister en Lingüística.

Correo electrónico: lagh@utp.edu.co

* Artículo de reflexión 


\section{EL PENSAMIENTO SISTÉMICO Y SUS RELACIONES CON EL ÁMBITO EDUCATIVO: DEL PARADIGMA LINEAL A LA TRAMA CIRCULAR}

《Esto sabemos. Todo está conectado como la sangre que une a una familia [...] Lo que le acaece a la tierra, acaece a los hijos e hijas de la tierra. El hombre no tejió la trama de la vida; es una mera hebra de la misma. Lo que le haga a la trama, se lo hace a sí mismo»». Ted Perry (Inspirado en el Jefe Seattle). (De Noguera, 2004, p. 70).

«La vida personal, la expresión, el conocimiento y la historia avanzan oblicuamente, y no directamente, hacia fines o hacia conceptos. Lo que se busca demasiado deliberadamente, no se consigue». Maurice Merlau-Ponty. (Castro, 2005, p. 220).

El problema no son las cosas que se advierten diferentes en el mundo, el problema es la concepción de quien ve las cosas en el mundo [...], ya como inmanencia pura, ya como dinámica holística, cuando no impura. ${ }^{1}$

(Giraldo, 2015)

«Toda innovación conceptual demanda una justificación precisa y debe delimitar las situaciones donde permite nuevas predicciones». Ilya Prigogine. (Prigogine, 1997, p. 15).

\section{Introducción}

En el presente artículo me propongo abordar la tesis propuesta por el físico Fritjof Capra quien ha analizado nuevas formas de comprensión científica de la vida en todos los niveles de los sistemas vivientes en sociedad; a su vez, relacionarla

\footnotetext{
${ }^{1}$ Esta idea deriva de la reflexión propia, al contrastar el pensamiento lineal y el pensamiento holístico o plural, en el ámbito académico-educativo, tal como lo asumo a lo largo del presente artículo.
} 
con los diálogos entre educación, comunicación y cultura, sustentados a partir de visiones teóricas y/o paradigmas circulares que han superado la visión lineal de occidente, desde miradas apartadas de la tradición y acciones fundamentadas en los campos más fuertes de la ciencia dinámica, la filosofía posmetafísica, los estudios culturales holísticos, la comprensión del lenguaje naturalista, entre otros.

Capra, en su libro La trama de la vida (1998), nos habla de investigaciones, estudios, divulgaciones en donde la percepción de la realidad y sus postulados se extienden con profundas implicaciones a otras áreas de las ciencias naturales y sociales, como la biología, la ecología, la política, la educación y la vida cotidiana: enfatizando en todos ellos la necesidad de asumir una nueva comprensión del universo en el que nos encontramos como un todo en el que, para entender sus partes, es indispensable adentrarnos en su interrelación con los demás fenómenos que lo conforman. Su mirada está fundada en determinar que la naturaleza de la realidad es un proceso creativo e interconectado en donde nada puede ser entendido aisladamente, sino por su pertenencia a la infinita y extensa danza de la creación.

Para Fritjof Capra, una nueva comprensión científica de la vida debe darse en todos los niveles de los sistemas vivientes: organismos, sistemas sociales y ecosistemas que permitan una mirada sistémica en el entendimiento del todo universal en el que nos encontramos adheridos como parte fundamental. Esta postura le apuesta a una reflexión filosófica y social de la ciencia moderna que en sí misma nos plantea cuestiones claves acerca de los fines humanos en todas las disciplinas y áreas del conocimiento para su interconexión, su profundización y humanización; lo que deja ver un interés holístico, pero explicativo para subsanar territorios fragmentados por el tiempo, el orgullo, el fanatismo, el poder a ultranza, las taxonomías disciplinares y la desatención del todo en la trama de la vida como consecuencia de la especialidad y la especificidad endogámica.

En este caso la tesis expuesta resulta precisa para comprender los procesos por los que está atravesando la educación, la comunicación y la cultura en los países latinoamericanos, en especial el nuestro, donde en gran medida y a pesar de los pensadores que han sospechado y delatado el pensamiento metafísico, las prácticas no se desligan — en su totalidad — de la apología a lo específico, del influjo positivista y lineal imperante por siglos; registrado bajo la tutela de la cientificidad pura, la razón de lo inobjetable y el judeocristianismo a usanza múltiple.

Así, en una primera parte expondré algunos elementos del paradigma metafísico y positivista que por décadas ha reinado en occidente. Su participación en el mundo científico y cotidiano como parte de un confinamiento cognitivo y conceptual duradero en el tiempo y en el espacio de creación y recreación del hombre, para concluir sobre la importancia del avance circular por conceptos, 
miradas y abordajes que expliquen el mundo educativo, comunicativo y cultural en el que se desencadenan otros ámbitos de interacción humana.

En segundo lugar, haré referencia a la intolerancia cultural y deshumanización social, como acciones resultantes del modo de producción capitalista, del consumo exacerbado en las sociedades, auscultado por la publicidad y los medios de (des)información, de la tecnologización y los conflictos o choques culturales que provocan la extinción de formas de vida cultural; la subyugación de unas, la desaparición de otras y la aparición de subculturas transgresoras de los órdenes tradicionales. Lo anterior, explicado desde una perspectiva actual del hombre y un abordaje del concepto de cultura y contracultura en situación de contienda, superposición o hibridez.

En tercer lugar, revisaré el pensamiento sistémico en Capra como una especie de interrelación y tejido final, logrado a partir de una red de voces teóricas que se hilan en especie de conductos e interconexiones que dialogan, discurren, cuando no, convergen en sentidos y encuentros cercanos. Por último, expondré mi perspectiva sobre el diálogo entre educación, comunicación y cultura, que hemos denominado la trama circular fundamentados en el enfoque teórico de Capra y su pensamiento sistémico, para desembocar en unas propuestas tentativas que revisan las implicaciones de nuevas formas de educar y comunicar, en medio de la diversidad de voces, culturas y miradas que inundan las tramas de la vida y sus procederes divergentes, convergentes, cuando no, ausentes.

\section{Elementos generales del paradigma metafísico y positivista en occidente: caracterización y ruptura en avanzada}

Los modelos platónico-aristotélicos han logrado traspasar las fronteras de espacio y tiempo en las que se han visto sumidos los pensamientos sobre el hombre y el universo. De ello da cuenta la historia, su acontecer investigativo y propositivo del cual nos hemos valido para comprender las relaciones entre esferas objetivas, subjetivas e intersubjetivas por las que han apostado las sociedades en sus diversas ontologías. Este legado ha sido sin duda un estandarte profundo en la manera en la que hemos mirado el mundo, sus constructos y los avatares más significativos. Si nos preguntáramos por qué nuestra historia occidental ha sido configurada con un modo de pensar binario más que tripartito o circular, las respuestas no podrían estar más ligadas a la escritura lineal perfeccionada por la cultura griega — de la cual todos derivamos - y al conocimiento taxonómico sobre el mundo otorgado por aquella.

Es claro que la sociedad helena no sólo aportó un modo de ser y estar en el universo desde visiones "únicas", "fijas" y "verdaderas" auscultadas por la permanencia de conceptos fosilizados e influenciados por la escritura; además, 
planteó un modelo educativo, social y político al que le fuimos haciendo el juego sin revisar ni objetar. Las explicaciones a lo ocurrido no serían pocas ${ }^{2}$. Sus más grandes disertaciones entrarían a observarse desde ámbitos científicos, educativos, sociales, culturales y en gran medida comunicativos con los cuales poder comprender cómo fueron comunicados y establecidos sus saberes como paradigma esencial para occidente. En últimas, cómo fue afectado el mundo directa o indirectamente por certezas y equilibrios puros. Apuesta que en tanto anidada en directrices de un pensamiento sistémico y complejo, resulta interesante para su demostración circular y para la proposición de nuevas formas de acercarse a la educación y el conocimiento.

No en vano, en esta ontología que venimos presentando abundaron conceptos como sustancia, esencias, eventos, estados, inmanencias, taxonomías, certezas, objetivismo, universalismo, en tanto hábitos intelectuales que permitieron vincular, cuando no, perpetuar, todo un pensamiento al devenir histórico; al devenir comunicativo en el que se ha instaurado el hombre y sus esquemas de abstracción.

Esto explicaría que en el siglo pasado se debatieran una serie de aconteceres del lenguaje que hicieron sentir la posible ruptura y la movilidad de los conceptos. Tal es el caso de Heidegger, quien llama la atención sobre el ser como verbo utilizado constantemente en frases atributivas de la forma [A es B] sin que se revise el sentido en su profundidad; pues según el autor en toda atribución hay permanencias, esencialismos en los que creemos a ojo cerrado. Así lo explica en El ser y el tiempo: «En todo conocer, enunciar [...] se hace uso del término "ser", y el término es comprensible sin más» (1974, p. 13). También el caso ironizado por Nietzsche, en El ocaso de los ídolos, así lo demuestra: «iQué maravilla que más tarde el hombre haya encontrado siempre en las cosas solamente aquello que había colocado en ellas!» (1966, p. 417). A pesar, en algunos reductos educativos, científicos, académicos y sociales, las consecuencias del paradigma lineal y positivista aún se experimentan. Las permanencias han quedado instauradas en y desde las reflexiones tradicionales sobre la filosofía, el lenguaje, la psicología, la sociología, la antropología, entre otras disciplinas que entraron en la esfera de la objetividad y el compromiso con la verdad, la demostración, el absolutismo y un universalismo de suyo alienador.

Tal como ocurriera con la reflexión filosófica clásica, el pensamiento razonado del siglo XVII retornó a una metafísica despiadada, a tono con la teología y el moralismo asentado en la esfera objetiva del mundo, desde la cual explicar todo

\footnotetext{
2 Para una ampliación de este tema, se recomienda abordar el capítulo undécimo: «El re-encanto del mundo o la tercera cultura», del libro Termodinámica y complejidad. Una introducción para las ciencias sociales y humanas (2005), del filósofo y pensador Carlos Eduardo Maldonado.
} 
el acontecer del hombre para comprender su cosmos circundante, su periferia activa, más que el mundo interino, subjetivo, cuando no, descentralizado. Ideas como la razón pura en Kant, advertirían de una influencia inscrita en el tiempo y en la anfibología descubierta en el pensador alemán, quien hábilmente hubo de moverse entre aguas razonadas y teológicas puestas en evidencia en su imperativo categórico ilustrativo y de paso limitante. Pues no hubo instrucción más cíclica y retornante a orígenes cristianos que su especie de mandamiento teórico-moral, propuesto desde la universalidad de una ontología sumida en un solipsismo abrumador.

En consecuencia el paradigma metafísico y positivista fundado en el binarismo abstracto, inundaría las reflexiones posteriores del hombre en su constructo del mundo y las teorías que lo explicasen. Ideas románticas del XIX en ámbitos como el lenguaje y la literatura así lo confirman. Las concepciones inauguradas en la lógica de Carnap, Russell, Wittgenstein —en sus primeros postulados—, Frege, acentúan la perspectiva especular que tuvo lugar en los estudios del lenguaje entendido desde la univocidad y la transparencia, como si el lenguaje fuese fiel reflejo de la realidad. Lo que sería comprendido como la relación ineluctable entre el lenguaje, el pensamiento y el mundo, o lo que es lo mismo: entender que las categorías lógicas del lenguaje reflejaban el mundo, liberado — _egún esta corriente- de la ambigüedad, las confusiones y los múltiples sentidos que de suerte acaecen cuando el discurso muta en significantes afectados, vivificados, metaforizados, cuando no subjetivados para otros... ${ }^{3}$

Esta etapa precientífica acuñaría conceptos dicotómicos que, en tanto hijos de la tradición judeocristiana, harían carrera en el siglo XX en un positivismo de corte conductista "beahaviorista" ${ }^{4}$ infestado de dualismos y exclusiones

Este contraste se puede evidenciar en las disquisiciones realizadas entre pensadores representantes de la concepción especular del lenguaje: Wittgenstein en sus primeros postulados, Gottlob Frege, Bertrand Russell, Peter Strawson, Carnap y representantes de la corriente naturalista como Wittgenstein en sus postulados tardíos, John Austin, John Searle y Paul Grice. Los primeros asumen el lenguaje como fiel reflejo de la realidad, mientras los segundos niegan toda conexión con la realidad directa, dejando la responsabilidad del significado a los usos y los contextos de enunciación.

${ }^{4}$ Naturalmente que el confinamiento cognitivo y conceptual al que estuvo expuesto el mundo científico, no solo hizo carrera en sí mismo. También este atajo dirigiría su mirada a los ámbitos de la vida cotidiana en la que el hombre expresaría toda su humanidad atravesada por la reflexión religiosa y científica. Estas, en avanzada, pulularon por épocas de creación y recreación de las sociedades y sus comportamientos más singulares. En especial, este confinamiento tuvo en dichos campos, amplios espacios en los que fertilizar sus fundamentos. El primero, el ámbito teológico, en el que la promesa del "más allá" tuvo eco en el conglomerado social; el segundo, el ámbito científico-educativo, en el que el conocimiento fue limitado a razones y certezas del "más acá". Estos dos espacios de interacción y conocimiento, harían que el ser humano en su cotidianidad, mantuviese firme ideas o redes de conceptos característicos de la metafísica y el objetivismo abstracto,

Revista Filosofía UIS, Vol. 15, No. 1, enero-junio de 2016 pp. 279-312 
mutuamente proporcionales en todas las disciplinas emergentes. Tal es el caso de la ciencia del lenguaje en la que valores oposicionales como significantesignificado, lengua-habla, sincronía-diacronía, sintagma-paradigma, individuosociedad, tendrían su protagonismo para la explicación de un mundo fundado en las segregaciones, estructuraciones y distinciones. Lo mismo ocurriría en áreas del conocimiento "menos blandas" (física, matemáticas, biología) que optaron por inscribirse en conceptos que denotaran certeza, equilibrio, límite, exclusión y linealidad; cimentados en lo infalible, mensurable, cuando no demostrable e inobjetable. Así, se puede advertir que los estudios del lenguaje en pleno siglo $X X$, fundados en una mirada metafísica clásica y en un pensamiento estructural, atravesarían descollantes gran parte de las ciencias humanas y sociales, pues durante mucho tiempo el lenguaje fue visto como un código abstracto que existía independientemente de los sujetos que lo utilizaban. Era visto como el producto de una relación neutra establecida entre un emisor y un receptor, que agotaba su significación en sí mismo (codificación y decodificación). Era simplemente una especie de objeto transparente cuyos niveles de organización y de estructura podían ser fácilmente observables a través de comparaciones, transformaciones y analogías.

Esta experiencia determinaría las trazas más fecundas sobre las cuales montar el trasegar del humano en su frenético encanto plagado de promesas, certezas, equilibrios y/o metarrelatos poco convincentes, como las ideas de progreso y modernidad; que según Habermas (1989), ha constituido un proyecto débil que no ha consolidado sus objetivos, que no ha logrado sus propósitos y, en consecuencia, no se ha podido plantear una visión posmoderna auténtica, ya que no tendría lugar.

Los dos ámbitos mencionados como posibilitadores de un confinamiento conceptual y cognitivo en el hombre, darían qué pensar en lo posterior. No obstante, su influjo marcó una tradición en la vida cotidiana del siglo XX cuyo ropaje abrasador es todavía en nuestros días, una especie de atadura de la que desatarnos completamente se ha convertido en una tarea difícil que solo un pensamiento complejo puede surcar. Nos referimos a la dinámica social relacionada con las

\footnotetext{
representados en el positivismo. Según Glosario de filosofía (s.f.), se trata de un: Neologismo procedente del inglés "behavior" utilizado para referirse a la escuela psicológica fundada por J. B. Watson en 1913 (que se convertiría en la escuela predominante en los Estados Unidos hasta los años sesenta, en que será desplazada por el cognitivismo).En la actualidad se suele utilizar más el término "conductismo" para referirse a dicha escuela, cuya característica más significativa es la de considerar la psicología como la ciencia de la conducta observable y manifiesta del organismo, ya sea animal o humano, en contra de la concepción tradicional de la psicología que se centraba en el análisis de los fenómenos de la conciencia, estudios que, por su carácter introspectivo, consideraron los conductistas que escapaban a la metodología experimental, que debería ser lo propio de una verdadera ciencia como se pretendía que fuera la psicología (párr. 1-2).
}

Revista Filosofía UIS, Vol. 15, No. 1, enero-junio de 2016 pp. 279-312 
prácticas religiosas, cuyas promesas, ritos, pócimas y encantos, han provocado una suerte de afincamientos moralistas en una gran parte de las capas sociales bajas, hasta las más respetadas altas capas políticas, mediáticas y oligárquicas de la sociedad latinoamericana. Lo que ha provocado una profunda conexión con la emoción del hombre y lo ha invitado a una creencia desmesurada, desproporcionada y alejada de una mirada explicativa, a tono con la experiencia mediata e inmediata de la actualidad y la realidad social.

Por su parte, muy alejada de la conexión emotiva, del encanto teológico o publicitario, las prácticas educativas han experimentado una especie de quietud, demostrado en las formas de enseñanzas paquidérmicas, exegéticas y poco operantes para el despliegue de categorías intelectivas que den qué pensar en los contextos: científico y socio-cotidiano. Lo que ha provocado un panorama decepcionante en el contexto global histórico y, en especial, en el contexto latinoamericano del siglo XXI, en donde en muchos reductos de educación básica, media y superior, aún se experimenta el estancamiento. Esto se sucede, por fortuna, en medio del contrapeso que movimientos y apuestas de sentidos divergentes y ondeantes de banderas de la sospecha, la crítica y el deconstructivismo, entre otras, realizan con pretensiones de construir una nueva red de conceptos y pensamientos; en el marco de una visión global que apueste por soluciones complejas e intervenciones con múltiples variables en los diferentes fenómenos humano-científico-culturales, como el pensamiento sistémico de Capra nos lo invita a ver.

Así pues, lejos de entenderse los fundamentos de la antigua Grecia como modelos obligados, a la manera reflexiva de Maturana (1992), por los cuales trasegar la vida humana y su camino atestado de certezas y razones, la actitud de sentido, la concepción de mundo, estaría en comprender esta mirada metafísica como una suerte de confinamiento ontológico en el que generaciones de pensadores y académicos cayeron víctimas, pues el protagonismo de la subjetividad y la no neutralidad del lenguaje, tal como lo plantea Serna (2007), fue solapado durante siglos. (Diríamos: escondido, latente, esperando la trama de la vida y su cíclico devenir). No obstante en esta discusión, se comprende lo que desde una postura crítica y concluyente leemos en Ontologías alternativas de Serna Arango: «La tradición académica — en sus líneas más gruesas - ha padecido, en cambio, un cierto confinamiento ontológico, cuyo eje de coordenadas lo constituyen el objetivismo y el universalismo» (p. 7).

Naturalmente, es a partir de esta fundamentación que ha venido configurándose a través de las corrientes del pensamiento humano, que reconocemos la supremacía de lo que hemos denominado la trama circular de la vida, que — en todo casosubvierte naturalmente el orden artificial y lineal creado por el hombre en su constante tránsito por las esferas del mundo: objetiva, subjetiva e intersubjetiva (Husserl, 2013; Bühler, 1934, Habermas, 1984 y 1990; Ramírez, 2007). 
Del mismo modo, después del denominado giro lingüístico, hemos podido registrarlo en la vida académica, filosófica y en alguna medida sociocultural, que ha venido delineando pensamientos y acciones de distinto orden; cuyas implicaciones permiten determinar cómo en el mundo de la vida y de la ciencia, los logros acumulativos del pasado, se convierten en soportes susceptibles de crítica y renovación en el presente, pues lo que ha sido cierto ayer, ya no lo será mañana. Tal fue lo acontecido con el lenguaje y su estudio desde una perspectiva naturalista anidada en el giro lingüístico, alejada del estilo plano y el significado lineal-proposicional de los enunciados (Nietzsche, Wittgenstein, Deleze, Derrida, Rorty, Austin, Searle, Grice), a partir de lo cual el paradigma inmanente y absolutista fue puesto en duda y propició profundos detonantes para un pensamiento diverso y sistémico, como será mostrado en la parte final de este diálogo sistémico. En esta dirección, lo revela Rorty, cuando expresa:

En lugar de metáforas del acercamiento a algo distinto a nosotros mismos, deberíamos usar metáforas de expansión: de hacernos mayores y mejores. A medida que Newton reemplazó a Aristóteles y Einstein a Newton, nos hicimos personas mayores y mejores; personas que podían vincular más cosas, sintetizar más datos, registrar más fenómenos, proponerse y llevar a cabo más proyectos. En la medida en que una religión del amor ha reemplazado a una religión de la ley, hemos llegado a ser personas con mayor capacidad de simpatía. Tenemos menos tendencia a excluir, a prohibir y a anatematizar. Tenemos una mayor tendencia a aceptar o, por lo menos, a tolerar. A medida que emergemos del mundo de nuestros padres y entramos en el mundo constituido por la música, los libros, las películas y las modas de nuestra generación, ampliamos nuestro juicio acerca de nuestras posibilidades. Cuando nos enamoramos, nos volvemos seres humanos mayores y mejores: más libres, más abiertos y más capaces de disfrutar. Cuando derrocamos a un tirano sucede lo mismo: se abren posibilidades que antes estaban cerradas. Nuestra imaginación se libera (2002, p. 10).

Con todo, lo anterior nos invita a reconocer — en sintonía con Capra- que una nueva comprensión científica de la vida debe establecerse en todos los niveles de los sistemas vivientes, los cuales permitan miradas organizadas, integrales para el entendimiento del todo universal en el que nos encontramos abrazados como parte esencial. Pensamiento que resulta justo para comprender los procesos por los cuales franquea la educación, la comunicación y la cultura en los países latinoamericanos; en especial el colombiano, donde en gran medida las prácticas educativas y sociales no se han desligado, en su totalidad, de la apología a lo específico, direccionadas por el influjo positivista y lineal que ha imperado en occidente, bajo la tutela de la cientificidad pura, la razón de lo inobjetable y el judeocristianismo en sus múltiples derivaciones. 
De allí que en definitiva se entienda los diálogos entre educacióncomunicación y cultura, como espacios vitales para la comprensión del hombre y del mundo en tanto que sistemas en armonía, circularidad, pero también en caos, desequilibrio, subjetividad e hibridez; con lo cual pensadores contemporáneos — como se expondrá en adelante- estarían en sintonía, concordancia o igual dirección reflexiva, animados por la sospecha, la crítica, la conciencia y la deconstrucción de apuestas de sentido pasadas. Pensadores que, en consecuencia, son situados en discusión con el propósito de mostrar que la ruptura y el olvido del paradigma lineal son posibles y necesarios, en función del paso progresivo hacia la comprensión de la trama circular del hombre y sus objetos de estudio..., ya desde el caos o el desequilibrio, ya desde la subjetividad o la hibridez.

\section{Deshumanización social e intolerancia cultural: icontraculturas en conflicto comunicativo?}

Como consecuencia de toda una tradición educativa, sociocultural y teológica instaurada en un pensamiento metafísico, cuando no, binario, en donde lo individual se contrapone a lo social, lo falso a lo verdadero, lo intangible a lo tangible, lo indemostrable a lo demostrable, la creencia a la razón, lo bueno a lo malo, lo feo a lo estético, el rico al pobre, lo mundano a lo sacro, lo viejo a lo nuevo, lo divino a lo infernal, entre otras dicotomías clásicas y duraderas a través de la existencia y nuestro modo de ver, la deshumanización y la intolerancia cultural entraron en carrera desenfrenada, conflictiva y contradictoria. Las paradojas abundan. Aún más, cuando lo que se habla es distinto de lo que se hace y lo que se dice es diferente de lo que se comunica, en muchas de las prácticas educativas, sociales, políticas, religiosas y culturales. Por fortuna no todas, pero sí en gran parte de ellas en las que el impacto de nuevas formas de educar, comunicar y socializar resultan indispensables, cuando no, prioritarias para nuestros días.

Este comportamiento en gran proporción intolerante, deshumanizante, decadente y dualista — como se ha mostrado — fue marcado por el pensamiento platónico-aristotélico y judeocristiano, así como por las promesas de la modernidad y su proyecto progresista. Por un lado, el modo de producción capitalista que ha sobrevivido hasta nuestro tiempo — sin botón de apague- marcó un modo de vida sumido en el consumismo arrasador y una especie de apariencia que todavía pervive en la estética falseada, en la ilusión, lo artificioso y la extremosidad, muy cercanas a las del período Barroco y el Rococó en el que dichas características cruzaban el pensamiento, las costumbres y la cultura del hombre de la época. Por otro lado, el protagonismo de la publicidad y los medios masivos de (des) información, han auscultado lo que bien podríamos denominar un modelo vergonzante para el rescate del ser sociocultural y su humanización, pues grandes segmentos de sus mensajes están siendo comunicados para la activación del instinto, la emoción y en consecuencia el uso y el descarte sin control; lo que 
ha sido registrado por grupos ecologistas, alternativos, antropólogos y críticos socioculturales.

De otra parte, el crecimiento tecnológico nos ha hecho caer en el abismo de la invención sin cesar, en la incesante búsqueda del bienestar humano. Alejado del pensamiento, de la creación en el sentido más originario del término, como resultado del influjo de la máquina que todo lo posibilita, que todo lo genera. Desde una convicción premonitoria, diríamos que se restaría protagonismo a la función creativa del cerebro humano en etapas posteriores de su existencia. Algunas de estas razones obedecen sin duda a la escritura tecnologizada, sinecdocal, reduccionista y transcreada (símbolos, memes, gráficos, emoticones) ${ }^{5}$, a la ergonomía que nos provee la tecnología en casa, oficinas y lugares múltiples en los que "el mundo se encuentra a nuestros pies", a las facilidades para encontrar información y personas (virtuales) en cualquier punto geográfico de nuestro globo terráqueo; entre otras, que han contribuido a que paradójicamente el mundo se achique y seamos, en términos de Nussbaum (1999), ciudadanos del mundo, pero también a que perdamos en gran medida la humanización, cuando los objetos creados toman el control de nuestras vidas y se vuelven sobre nosotros por influjo directo de la automatización tecnológica y la reducción del pensamiento creativo, en su sentido más puro.

Sin duda, a grandes rasgos, estas han constituido las formas como la deshumanización ha venido haciendo carrera en nuestras sociedades. No obstante y como consecuencia del desbarajuste de la naturaleza humanística, la intolerancia cultural ha entrado en conflicto con modelos educativos y sociales anidados en metafísicas, civismos, concepciones u ontologías pasadas, que si bien respetamos, también entendemos que en proporciones desmesuradas han sido la causa del deterioro, de la intolerancia por la otredad fundada por los dualismos, por su diferencia entre las acciones y concepciones de mundo tradicionales, alternas o progresivas. Desde una perspectiva sistémica, diríamos que dichas alternativas se han constituido para el entendimiento de variaciones educativas, comunicativas y culturales, donde el intercambio de identidades, culturas y valores es ya una constante en progresión.

\footnotetext{
${ }^{5}$ En relación con este tema las cargas están divididas. La comunidad científica y académica considera, por un lado, que nuevas formas de pensamiento y conexiones rápidas se logran con el influjo de la tecnología en los seres humanos, en especial los jóvenes, quienes se acercan con mayor facilidad a dispositivos que son creados para nativos digitales y su experiencia actual. Por otra parte, algunos psico-pedagógos, asumen que la automatización que producen estos dispositivos, restaría las capacidades intelectivas del joven y en el futuro sería muy posible una utilización reducida del cerebro, para la creatividad en el sentido más puro del término; toda vez que las prácticas que incita el mundo tecnológico y virtual, reduce cada vez las prácticas de escritura y lectura como lo hemos aprendido manual y tradicionalmente.
} 
Los conflictos culturales y las concepciones de mundo en contraste, han sido frecuentes en las diversas capas sociales en las que aún se respira un aire moralista, cuando no, de religiosidad insincera y falseada. En particular en ámbitos educativos, familiares y sociales, en cuyos epicentros las paradojas de enseñanza son el alimento de cada día para la conservación de modelos que ya no deben imperar, operar, ni atar los esquemas de pensamiento de la humanidad actual ni los cambios epistemológicos que se han venido validando, en acuerdo con las nuevas realidades surgentes en el ámbito científico, humano y social.

Sin embargo, aquellas costumbres metafísicas y positivistas dejan ver sus anacrónicos hábitos en medio de la comprensión de una educación, de una sociedad y una cultura que ya es otra. Estas formas recurrentes de conflictos por gustos, intereses, saberes, poderes, filiaciones, direcciones de pensamiento, tendencias, etc., que muestra nuestra contemporaneidad, han sido alimentadas por una suerte de contradicción en los mensajes, proporcionados por los medios masivos de (des)información. Esto sucede cuando la "realidad" real no se presenta, pero, paradójicamente, sí, cuando la representación creada y recreada es lanzada para confundir, cuando no, generar expectativas ilusorias, vínculos afectivos, deseos y necesidades que no existen. En consecuencia, esto ha hecho que culturas tradicionales o modos de ver el mundo afincados en la comprensión del mundo clásico, se contrapongan con las culturas progresistas que revisan la realidad como construcción social, colectiva, cuando no híbrida (Lefevbre, 1972; García Canclini, 1990).

De ahí que los choques culturales provoquen la extinción de formas particulares de existencia o la subyugación de unos modos de asumir el mundo en otros, como bien podríamos mirarlo en las dinámicas de diversas culturas clásicas, surgentes, híbridas y contraculturas que optan por caminos de comprensión del mundo desde una óptica o tribuna diversa, en oposición a una visión tradicionalista, cerrada y sin duda miope. Ejemplos de ello sobran. No estarían más lejos que de la contraposición entre modelos de familias clásicas y modernas; entre miradas antiguas hacia la conducta de los jóvenes y miradas actuales; entre la educación tradicional y la transgresora; entre filosofía antigua y moderna; entre la metafísica y la posmetafísica, entre la concepción especular del lenguaje y la naturalista, para citar solo algunas. La crítica filosófica, literaria, lingüística, sociocultural y antropológica contemporánea así lo registra. Y es en ellas en las que los caminos de tramas circulares en búsqueda de diálogos educativos, comunicativos y culturales, cada vez más — como se teje en esta apuesta— toman significativa fuerza.

En un tono atinente con la mirada que se sostiene a lo largo de esta apuesta, es evidente lo anterior en Rorty, cuando desmitifica y da qué pensar sobre los ámbitos: científico y religioso, en dos momentos de marcada diferencia: 
La llegada del cristianismo, de la Ciencia Nueva del siglo XVII y las revoluciones democráticas de finales del siglos XVIII eran cambios que no cumplieron los criterios previamente conocidos de lo que es una buena religión, una ciencia buena ni una buena política. En cambio, hay que verlos como cambios de nuestro juicio acerca de lo que pueden ser la religión, la ciencia y la política. Cada uno de estos cambios ha ampliado nuestra imaginación. Los logros de esta clase establecen sus propios criterios. Crean el gusto por el cual serán juzgados. Hacen pedazos las barreras culturales y disciplinares, rompen la corteza de la convención y liberan energías encerradas (2002, p. 11).

Naturalmente que lo descrito habrá de comprenderse como generación causada por el influjo inexorable del tiempo y el cambio normal, cíclico del hombre y sus sistemas. Lo cual, en los diálogos entre la educación actual, las formas de comunicar que deben darse y la cultura abierta, opera con gran protagonismo — como lo sugiere Rorty — en las concepciones de mundo vigentes, con las cuales tejemos el pensamiento sistémico capriano. Pues su percepción de la realidad, conecta con las ideas de totalidad, relación, hibridez, movimiento, desequilibrio, caos, error, desconexiones, incertidumbres y subjetividades, propias de pensadores al margen de la linealidad y sí al lado de la ruptura, el desglose, la fuga y la comprensión de trama circular que mantenemos y que abre mundo para explicar al hombre, sus conexiones con la historia, sus fenómenos de estudio socioculturales, en nuevas formas de imbricación con el todo universal.

\section{Capra y el pensamiento sistémico: voces e interrelaciones contemporáneas}

El cambio de paradigma contemporáneo no podría estar mejor inspirado que en la concepción de mundo aportada por Capra y su teoría general de los sistemas ${ }^{6}$. En esta concepción relacional, de tejido, de redes de la vida científica y cotidiana en reflexión, se acentúan los más insospechados caminos por los cuales poder recorrer; que al decir del autor —a pesar de la tradición y algunos reductos que aún inquietan - la misma trama en sus entrecruces, la vida nos ofrece.

\footnotetext{
${ }^{6}$ La teoría general de los sistemas en Fritjof Capra, se establece a partir del reconocimiento de la cibernética, la hermenéutica, el pensamiento complejo y la autorreferencialidad. Obedece a la capacidad de analizar los fenómenos de la vida científica o cotidiana de manera circular, en lo que entiende, existe una observación de primer orden (input) y luego una observación de segundo orden (out put), en una especie de observación e interpretación desde adentro, cuyo despliegue lo reconoce como la autorreferencialidad o la comprensión desde metaniveles configurados por la experiencia y la capacidad para captar, discernir y organizar los sucesos. La cibernética planteada por el autor, se interesa en observar las pautas de conexión entre las cosas y los sucesos; lo que implica una hermenéutica o interpretación a la luz de Heidegger y Gadamer, según la cual es necesario comprender los relatos desde los contextos, la historia, pues cada relato está marcado por el todo y este por cada relato. Sin duda, esto supone un pensamiento complejo que desarrolla con suficiencia en la Trama de la vida. Una nueva perspectiva de los sistemas vivos (1998).
} 
Su pensamiento sistémico revela cómo todas las construcciones del hombre son modelos que pueden verse afectados, mejorados y aplicados en la consecución de una sociedad mejor educada, comunicada y si se quiere culturizada en los más amplios sentidos y valores sociales como políticos. Lo que no ha sido un proceder extraño ni al margen de pensadores contemporáneos, en la consecución de miradas convergentes hacia la proposición de ontologías nuevas que permitan la pluralidad, el cambio, el desequilibrio, el escape y la subjetividad. Esto, para una sociedad mundial que requiere de cambios profundos y renovaciones culturales fecundas; en particular, en el contexto latinoamericano que ha sido catalogado como tercermundista, en el cual los paradigmas clásicos para la educación y la construcción humana, en alguna medida subyugan el mismo desarrollo educativo, político y social; en una suerte de juego manipulador de los poderes hegemónicos que mantienen su disputa con pensadores de avanzada y críticos del status quo, en el que desean mantener a las mentes más promisorias, transgresoras, provocadoras e inteligentes. Capra, en sus planteamientos asume en cuanto a la problemáticas del universo y del ser humano lo siguiente:

Los problemas del mundo deben ser contemplados como distintas facetas de una misma crisis, que es en gran parte una crisis de percepción. Deriva del hecho de que la mayoría de nosotros, y especialmente nuestras grandes instituciones sociales, suscriben los conceptos de una visión desfasada del mundo, una percepción de la realidad inadecuada para tratar con nuestro superpoblado y globalmente interconectado mundo (1998, p. 26).

Este planteamiento de entrada denota unánimo de relación entre macrosistemas (cultura, subcultura, ideología), mesosistemas (familia-escuela, trabajo, pares) y microsistemas (relaciones con padres, familia, escuela) en la trama de la vida. Se trata de una perspectiva que hila el acontecer de la naturaleza, el cosmos, el desarrollo humano y los sistemas sociales que detentan comportamientos diversos en acuerdo con los niveles educativos, los poderes adquisitivos, administrativos y políticos. Nos hallamos sin duda en el reconocimiento de un mundo que imbrica todo casi de manera imperceptible hasta sus últimas consecuencias. El problema con esta dinámica en la que llama la atención Capra, no es que este comportamiento se presente con características holísticas. El problema radica en la poca conciencia del hombre para reconocer las afectaciones que se causa a sí mismo cuando irrumpe, amenaza o destruye partes de los sistemas en los que configuramos nuestro existir. Por ejemplo, el medio ambiente, el ecosistema y los sistemas de instituciones públicas, que constituyen una de las principales causas del desequilibrio económico y el descontento social.

Una mirada integral como la presenta el autor, permite enlazar situaciones de educación y situaciones de comunicación nuevas en las que hemos venido entrando con decisión e irreverencia a pesar de cierto aire que continua denso, circulando un pensamiento metafísico y lineal. De la rebeldía dan cuenta algunos 
sectores de la intelectualidad y la educación media y superior en latinoamericana, cuyos ejes centrales han estado en el reclamo de la justeza, el equilibrio económico-social y la reivindicación de derechos y autonomía propios de toda educación libre.

No obstante, en acuerdo con su noción sistémica, las únicas soluciones viables son aquellas que resulten "sostenibles". Lester Brown del Worldwatch Institue, citado por Capra, comparte una definición sencilla, pero contundente sobre la sostenibilidad: «Una sociedad sostenible es aquella capaz de satisfacer sus necesidades sin disminuir las oportunidades de generaciones futuras» (26).

Sin duda esta definición se convierte en uno de los desafíos mayores de nuestro tiempo para la consecución de un diálogo educativo, comunicativo y cultural sostenible, en tanto permita que las sociedades futuras se comuniquen desde la colectividad, la solidaridad y el reconocimiento del todo universal como parte del yo subjetivo, que comparte y siente los mismos aires de naturaleza pura y vivificante.

De otro lado, el cambio de paradigma se sucede cuando las rupturas discontinuas y revolucionarias, se anidan — según Capra citando a Kuhncomo constelación de logros, conceptos, miradas, enfoques y valores, para que compartidos y usados por una comunidad científica, permitan la definición de problemas y la resolución legitima de ellos. Tal ruptura se explica cuando expresiones como "teorías de los sistemas dinámicos", "teoría de la complejidad", "dinámica no lineal", "dinámica de redes", abundan en un nuevo lenguaje para la comprensión de los complejos y altamente integradores sistemas de la vida que en tanto tramas circulares, dicen de las búsquedas y los reconocimientos heterogéneos en los que se han inscrito los nuevos pensadores de las ciencias sociales, humanas y exactas. Esto nos permite plantear incipientemente que un pensamiento circular aprovechando los logros acumulativos del pasado, es lo que nos posibilitará el avance en la construcción de categorías de pensamiento nuevas, para una sociedad mejor educada, comunicada y culturalizada como es nuestro propósito defenderlo aquí. En este sentido, nuestro acuerdo con Lucía Tobón de Castro, cuando plantea que:

[La] ciencia es un constructo racional elaborado por la mente humana para explicar fenómenos de su entorno, sean estos naturales, sociales o bien productos de su misma creación (valga aquí mencionar algunos a manera de ejemplos, vgr. la programación genética del hombre, la evolución cultural de los grupos humanos o las entidades matemáticas), la ciencia no puede hallarse fuera de la racionalidad humana, ni puede buscársele una función diferente a la formulación de leyes universales que expliquen por qué ocurren los fenómenos y predigan su comportamiento. Consecuencia de lo anterior es el hecho de que la ciencia no es ni verdadera ni falsa. 
Es simplemente veraz, falible e inacabada. Veraz en cuanto construye sistemas funcionales que remedan la realidad, falible porque es perfectible, e inacabada porque no puede ser un constructo cerrado, finito. Siempre está abierta al cambio. Puesto que es producto de la reflexión, la -ciencia es un proceso, es la evolución enriquecida del hombre en la que cada investigador va dejando huella, por esto no es posible atribuir su creación a un solo individuo o grupo ni desconocer cualquier antecedente porque sin él el proceso se rompería. De allí que en esta creación de la humanidad cada intento sea un eslabón insustituible por cuanto a medida que la ciencia se transforma, se va re-creando. [...] Todo esto justifica el que se considere a la ciencia como un cuerpo de teoría o un conjunto de leyes que se renuevan y actualizan. No como un código de normas que debe ser cumplido por todos y cada uno de los individuos. Visto el carácter abstracto de la ciencia comprendemos por qué ella crea metalenguajes y desarrolla formalizaciones que le permiten presentar sus resultados. Pero como en toda elaboración intelectiva hay niveles de abstracción y tipos de leyes. No todo en ella es extraño, enigmático (1989, p. 14).

Lo anterior me permite señalar que en la actualidad, a pesar de nuestros reductos metafísicos y las contradicciones sociales, culturales y educativas, se está tejiendo un nuevo modo de ver. Un nuevo modo de comprender la trama circular que desde un pensamiento sistémico construimos y proponemos como solución alterna, como modelo pedagógico latente para consolidar y desarrollar en las aulas latinoamericanas. Este modelo pedagógico, como lo trazaremos más adelante, tendrá que estar imbricando las relaciones que se tejen entre la vida cotidiana (gustos, intereses, diferencias, estéticas) y la vida académica (contenidos repensados) del estudiante; pues si para este lo que experimenta fuera del aula es importante, la educación tendrá que tenerlo en cuenta en sus prácticas de enseñanza. Y en este sentido cabría preguntarnos: ¿no es la reflexión de los fenómenos propios de la existencia, de la vida cotidiana, lo que en lenguajes académicos y especializados se estudia en las aulas? Ante esto conviene resaltar lo que Capra expresa:

El paradigma ahora en recesión ha dominado nuestra cultura a lo largo de varios centenares de años, durante los que ha conformado nuestra sociedad occidental e influenciado considerablemente el resto del mundo. Dicho paradigma consiste en una enquistada serie de ideas y valores, entre los que podemos citar la visión del universo como un sistema mecánico compuesto de piezas, la del cuerpo humano como una máquina, la de la vida en sociedad como una lucha competitiva por la existencia, la creencia en el progreso material ilimitado a través del crecimiento económico y tecnológico y no, menos importante, la convicción de que una sociedad en la que la mujer está por doquier sometida al hombre, no hace sino seguir las leyes naturales. Todas estas presunciones se han visto seriamente cuestionadas por los acontecimientos recientes, hasta el punto de que su reconsideración radical está ocurriendo en nuestros días (1998, pp. 27-28). 
Así, el cambio de paradigma en Capra, compromete una visión renovada de la percepción ecológica y espiritual. En lo que reconoce la diferencia entre una ecología superficial y una ecología profunda. En esta última, queda claro que, «reconoce el valor intrínseco de todos los seres vivos y ve a los humanos como una mera hebra de la trama de la vida» (29). A su vez «la percepción ecológica profunda reconoce la interdependencia fundamental entre todos los fenómenos y el hecho de que, como individuos y como sociedades, estamos todos inmersos en (y finalmente dependientes de) los procesos cíclicos de la naturaleza» (28).

En la misma línea, la ecología social, feminista, ética, psicológica, promueven en su mirada un cambio del paradigma mecanicista al paradigma holístico. En los primeros conceptos como materia, substancia, forma, cualidad, estáticidad, racional, analítico, reduccionista, lineal, manifiestan la quietud de un pensamiento anacrónico. En lo segundo, expresiones como: flujo continuo, organismo, vida, evolución, desarrollo, metabolismo, intuitivo, sintético, holístico, no lineal, conservación, cooperación, calidad, asociación, presentan una dinámica propia de los sistemas que, en tanto transiciones de la circularidad y en términos de uno de los grandes pensadores ilustres del XVII, Wilhem Von Humboldt representarían energía/dinamismo más que ergon/quietud.

En lo global, el pensamiento sistémico de Capra radica en considerar que las propiedades esenciales de un organismo o sistema viviente, son propiedades del todo que ninguna de las partes posee. Lo que le autoriza plantear que una de las propiedades sobresalientes de toda manifestación de vida es la tendencia a constituir estructuras multinivel de sistemas dentro de sistemas. Cada una de ellos — según Capra_ - forman un todo con respecto a sus partes, siendo al mismo tiempo parte de un todo superior. De ahí que emerjan las interacciones y relaciones entre las partes. Ejemplo de ello lo encontramos en el propio lenguaje, que como sistema, se teje con subsistemas que explican la totalidad de su naturaleza; esto es, los niveles de la lengua endógenos (fonología, morfología, sintaxis, semántica) y exógenos (pragmática, semiótica) que posibilitan la trazabilidad, la integralidad e interrelación para una comprensión amplia del lenguaje en acción. De lo que sin lugar a dudas, se desprenden otros sistemas creados y recreados a partir del sistema lingüístico que los soporta. Ya lo reafirmaba Capra, en otros apartados, cuando hábilmente reconocía los problemas del mundo como productos de la percepción sostenida a partir de los conceptos; en últimas, a reconocer que los problemas del hombre derivan en acciones no separadas de las concepciones del mundo en que nos establecemos.

Pensar sistemáticamente, entonces, supone comprender las conexiones, las totalidades, las relaciones, las pautas que en el mundo científico y cotidiano, la misma vida otorga. Estas nociones iniciáticas en el autor hacen que la profundización de su obra la encontremos en teorías que desprende entendidas desde la cibernética, la hermenéutica, el constructivismo y el pensamiento complejo. 
Como físico revolucionario, encuentra que es prioritaria la humanización de los mundos exactos en los que las subjetividades, las relatividades, las incertidumbres, también afloran como parte de un todo que se sostiene en la trama.

En coherencia con el pensamiento capriano, y como lo he sostenido a lo largo de lo expuesto hasta este momento, una mirada circular que deviene en destrucciones, construcciones, reconstrucciones y valoraciones siempre de suyo humanas, serían detonantes para un pensamiento sistémico aplicado en la educación y la cultura; en la consecución de miradas convergentes hacia la proposición de ontologías nuevas que posibiliten la pluralidad, la transformación, el desequilibrio, la fuga y la subjetividad, cuando no la responsabilidad con la otredad, su diferencia y el respeto por su participación cíclica en el constructo universal.

Miremos, ahora, cómo la relación de las teorías sistemáticas en Capra se sostienen en convergencia con la de otros pensadores contemporáneos no menos hábiles, pero sí partícipes como subsistemas del sistema que, en La trama de la vida, ha creado el físico austriaco.

En primera instancia, Edgar Morin (1999), propone la educación como una formación permanente, en la que la relación hombre-mundo debe establecer de fondo la racionalidad como arma contra el error y la ilusión dejados por las certezas del pasado. Para el autor es importante advertir como primer saber: la ceguera del conocimiento en tanto autocrítica necesaria para domesticar mitos e ideas añejas. Lo que da cuenta de una perspectiva autorreferencial en tanto es evidente cómo Morin propone una mirada en la que es consciente de su propia voz y las distancias en relación con mundos lineales. No obstante, arguye Morin que lo inesperado nos sorprende porque las certezas nos mantienen. El conocimiento permanente nos hará comprender que las informaciones aisladas son sentidos insuficientes para la comprensión del mundo. De ahí que en estos diálogos, el reconocimiento del contexto y la percepción global desde lo sistémico constituyan estados mentales para el encuentro de voces. Lo que resulta interesante como formas de conocimiento continuo, para hallar los sentidos en contextos globales de participación humana. Enseñar la condición humana, a su vez, es reconocer la identidad terrenal que nos asiste de múltiples maneras, como desde la hibridez lo muestra García Canclini en sus estudios culturales.

De otro lado, las teorías sistémicas de Capra tienen su morada en la reflexión del pensador francés, cuando al plantear saberes necesarios para la educación del futuro, revisa conceptos como autonomías individuales, según las cuales existe diversidad, facetas de lo humano, multiculturalidades, diferencias, destinos individuales y sociales entrelazados, de lo que se deriva la necesidad de comprender una era planetaria. Asumida como la posibilidad de la esperanza, nuevas creaciones humanísticas, responsables y solidarias con los hijos de la tierra. 
Que sin duda, conectan con la trama de la vida en la que solo seríamos una simple hebra en ella.

En la interconexión hallada entre Morin y Capra, encontramos cómo la reflexión del primero sobre los antagonismos que hemos descrito y sobre la muerte ecológica — que según el pensador francés se ha ocasionado por la actividad de todos los humanos- converge con las del segundo quien en su ecología espiritual y social, defiende la conexión con el cosmos como un todo que no debemos seguir destruyendo. Planteamientos iniciales que lo conducen a esbozar la necesariedad de enfrentar la incertidumbre en una época cambiante, ligada, conexa con otras y en donde nuestra realidad es la idea que tenemos de realidad. Esto es la subjetividad que aflora y nos permite reconocer en autorreferencia otras subjetividades en un mundo en el que el conocimiento es una aventura constante contra el error y la ilusión.

Sin lugar a dudas, la sistematicidad de las nociones de Morin en sintonía con las de Capra, deja esclarecer nuestra tesis de la importancia de encontrar el sentido del pensamiento sistémico en la educación, la comunicación y la cultura, para una pedagogía latinoamericana alterna, además de reconocer el paso del paradigma lineal a la trama circular. Esto no podría estar mejor vinculado que a otro de los siete saberes propuestos por Morin, según el cual, hay que enseñar para la comprensión en la empatía, la identificación, medio y fin de la comunicación humana. Tarea, según el escritor, para una educación nueva, en donde las prácticas educativas y comunicativas tendrán que implicar sistematicidad, relaciones y comprensión del mundo total.

Puesto que la incomprensión hacia la otredad es la destructora de relaciones humanas, de pluralidad de sentidos y la que revela la ignorancia sobre ritos y costumbres, no es preciso ni conveniente para las generaciones futuras que siga constituyendo una práctica animada en las escuelas; con el beneplácito de dinámicas científicas y educativas que tejen especificidades y solipsismos funcionando en sí mismos, pero que alejan la trama de la vida con la que irremediablemente tienen conexión. Como resultado, una ética del género humano será un saber que nos permitiría un control mutuo para la humanización, para el respeto de las desigualdades, para la democracia, la educación y la toma de conciencia muy cercana a la ecológica en Capra; pues en acuerdo con Morin: «si no se mantiene la autocrítica, la racionalidad, se arriesga a caer de nuevo en la llusión» (1999, p.8).

En esta circularidad, encontramos, en segunda instancia, una cartografía del conocimiento aportada por Francisco Varela, desde una mirada a la mutación de la historia de la mente y la naturaleza. En su perspectiva cognitiva, Varela, rescata «preocupaciones que afectan la vida de la gente y no se limitan a ser teóricas» (1988, p. 14). Se trata de un panorama para entender las ciencias cognitivas que 
analizan perspectivas actuales y comentan grandes corrientes ortodoxas que han recorrido estos dominios. En el ascender de su propuesta en su obra Conocer. Las ciencias cognitivas: tendencias y perspectivas. Cartografías de las ideas actuales, el autor deja ver cómo en los procesos neuronales y los procesos de conocimiento, la curiosidad permea los grandes desarrollos. Esta curiosidad es concebida como una grande epopeya de la ciencia que se convierte en práctica social, más que en un progreso lineal; en la que según su visión, la mente humana se advierte como el eje central del conocimiento, en tanto es necesario que el cerebro se vea como un todo y no por partes, pues no existen reglas definidas para que el cerebro opere. Las interconexiones masivas neuronales actúan en conjunto, en redes y los procesos son más eficaces para la comprensión, puesto que la cognición para el autor, no es más que un procesamiento de la información mediante la manipulación de símbolos que involucra múltiples transformaciones.

Se trata de una historia de acoplamiento que hace emerger un nuevo mundo, el cual funciona a través de elementos que se interconectan y producen cambios a partir de símbolos. Es precisamente a estos últimos, a los que el pensador chileno presta gran atención como parte fundamental de su hipótesis cognitiva; según la cual, derivado de las representaciones simbólicas, los seres humanos logramos la conexión entre la inteligencia y el mundo; en últimas, entre la ciencia y la vida.

En este sentido, estos planteamientos no dejan más que pensar que las conexiones de fondo existentes con el pensamiento capriano, le posibilitan a la teoría sistémica constituirse como fundamento válido y sustentado para explicar el mundo, los fenómenos, los sucesos, los contextos y el lenguaje con el que se abordan, pues preguntas de Varela como: ¿qué hace el cerebro?, ¿es la mente una manipulación de símbolos?, ¿puede una máquina comprender el lenguaje?, ¿cómo opera la simbolización en el cerebro humano?, ¿cómo funciona la cognición como emergencia de estados globales?, no admiten más para ver, sino la intensa relación con las pautas de conexión entre los sucesos y las cosas que detenta la cibernética, que comprende la hermenéutica, que asimila la autorreferencia y que revisa el pensamiento complejo.

Ciertamente, si entendemos que la vida no es una línea recta, estas nociones soportan la idea que he planteado sobre la relación del pensamiento sistémico con la educación y el paso hacia una trama circular en el entendimiento del proceder pedagógico, comunicativo y cultural; especialmente, en los ámbitos de educación latinoamericanos de niveles medios y superiores. De aquí que continuar hacia un propósito liberador, colectivo, holístico y diferente, es el camino a seguir animado por quienes han dado qué pensar o han provocado otras vías para conocer. Y es en ellas en las que la defensa se hace cada vez más férrea, desde la acción y la concepción de mundo que ha virado, cuando no poseído nuestro pensamiento y su práctica en directa correlación. 
Sorprende pues la cercanía. Aún más, cuando el entrecruce entre la ciencia y la vida es parte de lo que he fundamentado en otras aproximaciones que revisan la relación entre la educación y la vida. En concreto, entre la pedagogía de la vida y la vida en la pedagogía, cuyo trasfondo vivifica las discusiones antiquísimas y recientísimas sobre prácticas de enseñanza innovadoras, diferentes; como el planteamiento emergente de Varela para "conocer" deja verse: transgresor, emergente, hilado a las consideraciones caprianas y a nuestra apuesta de sentido en la cual se hallan diálogos que detonan, cuando no, provocan.

En correspondencia con sus aportes, la siguiente contemplación frente a la ciencia, soporta estas ideas que presentamos:

El fecundo diálogo entre investigadores, tecnólogos y público encierra un potencial para la transformación de la conciencia humana que yo encuentro fascinante, pues se trata de una de las más interesantes aventuras que hoy enfrentamos. [...] constituye un [...] aporte a este diálogo transformador (1998, p. 14).

Queda expreso que los sistemas complejos constituyen el tipo de pensamiento que este mundo solicita desde las interacciones $y / 0$ metamorfosis para las posibilidades del hombre futuro a la manera de Khun. No solamente en el mundo de la ciencia y sus avatares como hemos mostrado, sino en el mundo de la vida en el que hemos sido arrojados para el despliegue de todos nuestros entrecruces los cuales — sin lugar a dudas - no están por fuera del propio mundo, sino en sus tramas.

En esta línea de pensamiento ubicamos, en tercera instancia, las reflexiones acaecidas en la complejidad proporcionada por Humberto Maturana en su obra La objetividad. Un argumento para obligar. En ella, el autor plantea la explicación de la experiencia y de las relaciones humanas a partir de la siguiente pregunta: ¿cómo hacemos lo que hacemos en tanto observamos nuestro hacer? Pregunta que identifica otra de las amalgamas de redes y conexiones para la autorreferencia. Aquella desde donde surgen las posibilidades de conocimiento de las propias subjetividades y las de los demás. Es decir, su pensamiento constituye la oportunidad de entrar en una reflexión profunda sobre la concepción de mundo que tenemos. En tal sentido, Maturana sostiene: «En tanto el ser humano no es la medida de todas las cosas, como decía Protágoras, sí es el origen del mundo que vive» (1992, p. 11).

Así, esta mirada supone que el observador de la realidad aparece en la distinción del observar al hacer la pregunta por lo observado y el observar. Lo que traduce en la aparición de las acciones en las mismas acciones y no en supuestos ontológicos a priori. Esto se explica mejor cuando Maturana, en relación con el lenguaje aduce: «La explicación del lenguaje no reemplaza el lenguajear , y que 
el lenguajear ocurre en su ocurrir, en el fluir mismo de estar en el lenguajear, no en su explicación, aunque la explicación dice cómo ocurre» (10). Esto significa que la racionalidad para este pensador, está dada en la medida en que es la capacidad del hombre para hacer distinciones; esto es, la capacidad de distinguir distinciones. Lo que conecta con la emoción, con la apreciación que según él es lo que nos conduce a realizar cosas y/o acciones diferentes.

En tanto lo que nos hace humanos es lenguajear, en él ocurre el fenómeno de la autoconciencia, que se liga con la autorreferencia en Capra, y surge como dominio en el hombre para darse cuenta de sí mismo; de su propio modo de convivencia que se establece en el lenguajear. De ahí que en la siguiente valoración, Maturana invite a convivir en conversaciones, en armonías de vida, en armonías de conocimientos, pues según su perspectiva global, no hay armonía entre el ser humano y la naturaleza, producimos al infinito; lo que en Capra, muy en sintonía, aduce como el pensamiento sistémico ecológico:

Todo el vivir humano ocurre como un vivir humano en las relaciones humanas en la continua creación de mundos, ya sea en la ciencia, la técnica, la filosofía, el arte, o el simple convivir. ¿Y qué es la epistemología? ¿También es un modo de convivir? iSí! En verdad, ese es el tema de este libro: el vivir, y desde la comprensión del vivir y del convivir, ver que la realidad pertenece al explicar del vivir y el convivir humanos (1998, pp.28-29).

De otro lado, el trasfondo que ofrece Maturana con su planteamiento, vislumbra cómo la búsqueda por la objetividad desde apuestas pasadas, lo que han ocultado es un argumento para obligar a las adherencias sin más. Lo que tiene mucho sentido en su enfoque si pensamos que a través de la historia lineal, positivista y objetiva, lo que se ha trazado es la incesante búsqueda de la verdad, los universalismos y la homogeneidad totalizante. Baste para ello pensar en los argumentos para obligar como los que hemos descrito arriba - con la participación de Platón, Aristóteles, la Edad Media, la Ilustración, el siglo XX y sus derivaciones estructuralistas, positivistas cuando no judeocristianas. No obstante, como se percibe en esta ontología provocadora sobre la objetividad, la pregunta por lo que es la realidad, supone siempre argumentos racionales para justificar nuestras acciones. Según Maturana: «Esta pregunta por la realidad, determina cómo vivimos nuestra vida, así como nuestra aceptación o rechazo de otros seres humanos en la red de sistemas sociales que integramos» (1992, p. 14). Lo que en otras palabras el autor resumiría en considerar que, «todo vivir humano ocurre en conversaciones y es en ese espacio en el que se crea la realidad en la que vivimos» (14).

Las explicaciones de esta otra cercanía, que procede de la biología del observador, del lenguaje y del conocimiento, son atinentes con el pensamiento sistémico capriano. Solo al considerar las cegueras que nos ofrece la objetividad pensada desde argumentos para obligar, para adherir sin más ni más hacia una 
"razón", avistamos lo que significaría consolidar para los diálogos educativos, comunicativos y culturales en Latinoamérica, una nueva manera de entender la objetividad (entre paréntesis) ${ }^{7}$ a la luz de Maturana, como la construcción dentro de nuestras subjetividades. En lo que la educación y las relaciones entre profesorestudiante-comunidad educativa, inviten al respeto por el otro; en una suerte de matriztica que al decir del biólogo y epistemólogo chileno, promuevan la colaboración e interacción; pues este reto, esta propuesta, debe dar cuenta de la resolución de problemas, de puntos ciegos y conflictos humanos a partir de la sabiduría, del reconocimiento del otro, su subjetividad y del amor que debe ser por excelencia el fundamento de cualquier ciencia en la trama de la vida. En especial en esta trama circular como progresión de una proposición en espiral que construimos, cuando no nos construye.

En este entrecruce de voces que se fraguan, encontramos imbricado, transversal a la teoría sistémica capriana, la tesis del antropólogo y crítico cultural argentino Néstor García Canclini, en su libro Culturas híbridas: estrategias para entrar y salir de la modernidad, según la cual, «la hibridación como proceso de intersección y transacciones, es lo que hace posible que la multiculturalidad evite lo que tiene de segregación y pueda convertirse en interculturalidad» (1990, p. 20). En sus argumentos, el autor sostiene que las ciencias sociales han importado muchas nociones de otras disciplinas, sin que las invaliden las condiciones de uso en la ciencia de origen. Pero que no hay por qué detenerse en la migración de términos, sino en las operaciones epistemológicas que sitúen su fecundidad explicativa y sus límites en el interior de los discursos culturales. Razones que le asisten para preguntarse sobre si permiten aquellas migraciones conceptuales entender mejor o no, algo que permanecía inexplicado. Lo que en consecuencia, deja entrever las implicaciones que tienen las tramas circulares para enfrentar todas las vicisitudes humanas de otras maneras; construyendo nuevas redes de conceptos para cambiar las acciones que, en todo caso, no se separan de estos.

De allí que el contexto científico en el que García Canclini ubica su tesis, esté dado en el campo de las ciencias sociales, en el cual «hay que comprender los estadios en los que se mueve una disciplina o un campo del conocimiento» (1990, p. 13). Para ello arguye que en el ámbito científico de las ciencias humanas y sociales, una disciplina cambia cuando algunos conceptos irrumpen con fuerza, desplazan a otros o exigen reformularlos, v.gr. contradicción, mestizaje, sincretismo, transculturación y creolización. Tal es el caso de su crítica cultural que mejora lo que ha entendido por hibridación en sus miradas anteriores, reconociendo

\footnotetext{
7 Se trata de una expresión acuñada por el científico chileno Humberto Maturana para referirse al papel de la objetividad en los criterios de validación de las explicaciones científicas, que para este autor debería ser puesta "entre paréntesis" ya que el conocimiento es una construcción en el lenguaje con la intención de captar de una realidad independiente del observador. Este concepto tradicional de la objetividad lo denominaría como objetividad trascendental.
}

Revista Filosofía UIS, Vol. 15, No. 1, enero-junio de 2016 pp. 279-312 

educativo: del paradigma lineal a la trama circular

las ventajas de utilizar la expresión: "culturas híbridas" como término cargado de equivocidad. Lo que sugiere pluralidad, polisemia y una discusión nueva del sentido desde una epistemología que reorganiza la visión sobre la hibridez cultural en la siguiente dirección: «procesos socio-culturales en los que estructuras o prácticas discretas, que existían en forma separada, se combinan para generar nuevas estructuras, objetos y prácticas» (14).

Ciertamente, este abordaje —en tanto sistémico- dialoga también con la focalización capriana. Toda vez que se advierte en García Canclini que las propiedades esenciales de un sistema viviente como el cultural analizado, son parte del todo que ninguna de las partes posee. Aquí, se va explicitando cada vez más la expansión de la teoría sistemática que, como hemos enunciado, atraviesa en relación de contenencia todas las visiones confrontadas.

Lo expuesto por Capra como cibernética de segundo orden, hermenéutica y pensamiento complejo, se materializa en García Canclini, cuando al ocuparse de temas como el consumismo, la globalización y la culturización, entrevé en sus nociones pretensiones conexas con la circularidad. Por ejemplo, al referirse a la globalización como condición para hablar y reconocer conceptos como mestizaje e hibridación, propone la misma globalización como desafío para configurar una segunda modernidad más reflexiva, que no imponga su racionalidad secularizante, sino que acepte pluralmente tradiciones diversas. Asimismo, al reconocer que la intensificación de la interculturalidad migratoria, económica y mediática, no solo genera fusión, sino confrontación y diálogo, devela el pensamiento sistemático, complejo, hermenéutico, autorreferencial y cibernético, que lo contiene.

Según él, en este tiempo en que las decepciones de las promesas del universalismo abstracto han conducido a crispaciones particularistas, el pensamiento y las prácticas mestizas son recursos para reconocer lo distinto y elaborar las tensiones de las diferencias. De esta manera, advierte que solo las políticas de hibridación, podrían servir para trabajar democráticamente con las divergencias, para que la historia no se reduzca a guerras entre culturas. Con lo cual no deja de reconocer que la hibridación no es sinónimo de fusión sin contradicciones, sino que puede ayudar a dar cuenta de formas particulares de conflicto, generadas en la interculturalidad reciente y en medio de la decadencia de proyectos nacionales de modernización en América Latina. No obstante, reconoce que la hibridación fusiona estructuras o prácticas sociales discretas para generar nuevas estructuras y nuevas prácticas en las que surge la creatividad individual y colectiva; no solo en las artes, sino en la vida cotidiana y en el desarrollo tecnológico, en los cuales se puede entrar y salir de la hibridez.

En este orden, García Canclini, ofrece un desplazamiento del concepto de identidad a la heterogeneidad y la hibridación intercultural, cuyo entendimiento como proceso relativiza la noción de identidad y clausura la pretensión de 
establecer identidades "puras" o "auténticas". Esta idea alrededor de la identidad reafirma la nuestra según la cual no hay identidad, existe pluralidad; pues no somos unidad, somos muchos de acuerdo con los énfasis y los intereses en el mundo de la vida. Según Canclini:

Cuando se define una identidad mediante un proceso de abstracción de rasgos, de acuerdo con el pensador argentino, se tiende a menudo a desprender esas prácticas de la historia de mezclas en que se formaron; como consecuencia, se absolutiza, se rechazan maneras heterodoxas, se obtura la posibilidad de modificar la cultura y la política (1990, p. 11).

Consecuencias que en esta aproximación observamos desde otra orilla epistémica en la que se relativiza, se aceptan las diversidades y se abre mundo a los cambios culturales y políticos; esto, como implicaciones bondadosas para una Latinoamérica mejor educada, comunicada y culturalizada en la diferencia, el respeto y la tolerancia, alejada de tropismos abstrusos o caminos obligantes. Mejor no puede estar ejemplificado que en la siguiente consideración de Cornejo Polar (1996, p. 841), que citado por García Canclini, fusiona el concepto de hibridación con el de migración:

La migración como parte del proceso de hibridación, muestra la oscilación del sujeto entre la identidad de origen y la de destino. El sujeto acepta descentrarse de su historia y desempeña varios papeles "incompatibles y contradictorios de un modo no dialéctico": "el allá y el aquí, que son también el ayer y el hoy, refuerzan su aptitud enunciativa y pueden tramar narrativas bifrontes y - hasta si se quiere, exagerando las cosasesquizofrénicas" (20).

Todas estas relaciones de concepciones de mundo que hemos presentado en clave sistémica y autorreferencial, hacen que pensar en propuestas conceptuales y educativas nuevas, sean el horizonte próspero para el rescate de la educación actual en constante amenaza por frentes y reductos hegemónicos y oscurantistas. En suma, es nuestro acuerdo con García Canclini cuando indica que «estudiar procesos culturales más que llevarnos a afirmar identidades autosuficientes, sirve para reconocer formas de situarse en medio de la heterogeneidad y entender cómo se producen las hibridaciones» (18). Cómo se producen las "tramas de la vida", las "tramas circulares", que en avanzada, decantan estilos planos, estáticos o lineales.

En última instancia, las propuestas teóricas de Ilya Prigogine en El fin de las certidumbres (1997), de Peter Smith en El Caos (2001) y de Francois Julien en Un sabio no tiene ideas (2001), acentúan la mirada capriana sobre la trama de la vida que transversal ha viajado hasta aquí. Pues, el primero, acepta una nueva formulación de las leyes como necesariedad para comprender por qué la sociedad actúa con modelos de las ciencias clásicas fundamentadas en la certidumbre, el 
equilibrio y el orden. Esto, según el autor, ocurre porque hemos creado dispositivos como la política, la religión y el consumismo. No obstante, la invitación se centra en presentar la transformación de las leyes de la física y de la descripción de la naturaleza. Lo que conduce a destacar tanto en la dinámica clásica como en la física cuántica, las leyes fundamentales, la expresión de posibilidades y no de certidumbres. Mejor queda demostrado cuando Prigogine, complejiza la relación entre existencia, leyes, tiempo:

Llegamos así a la frontera de nuestros conocimientos en un ámbito donde razonamiento físico y especulación se delimitan con dificultad. Por cierto es prematuro hablar de demostración o de prueba, pero es interesante analizar las posibilidades conceptuales. Como veremos, podemos concebir hoy el big bang como un acontecimiento asociado con una inestabilidad, lo que implica que es el punto de partida de nuestro universo, mas no del tiempo. Si bien nuestro universo tiene una edad, el medio cuya inestabilidad produjo ese universo no la tendría. En esta concepción del tiempo no tiene principio, y probablemente no tiene fin (...) Asistimos a la emergencia de una ciencia que ya no se limita a situaciones simplificadas, idealizadas, mas nos instala frente a la complejidad del mundo real, una ciencia que permite a la creatividad humana vivenciarse como la expresión singular de un rasgo fundamental común en todos los niveles de la naturaleza (1997, pp. 11-13).

El segundo pensador, Peter Smith, entiende el "caos" como un artificio, desprovisto de sus connotaciones habituales. De acuerdo con el autor:

La teoría del caos no es más que la etiqueta popular asignada a un cuerpo de teoría sobre ciertos modelos matemáticos y sus aplicaciones. Una característica del "caos" es su dependencia sensible a las condiciones iniciales, es decir, que partiendo de dos estados iniciales muy similares un sistema caótico puede desarrollarse de maneras radicalmente diferentes (2001, p. 9).

De fondo, los sistemas dinámicos propuestos en sus diferentes modelos matemáticos y la dinámica compleja que soporta, dan cuenta de la relación con el pensamiento sistémico capriano y la reflexión educativa, comunicativa y cultural en el mundo de la vida. Así también, como de la no transparencia, la no linealidad de sistemas dinámicos, como el lingüístico con el cual operamos las concepciones que nos habitan; cuyas raíces empiezan a advertirse profundamente móviles en su devenir, que están ancladas en certezas sin porvenir. Finalmente, y en acuerdo con Smith (2001), << hay que aceptar las verdades múltiples y simultaneas, el relativismo epistemológico es una especie de orquesta $>>$ en donde la "trama de la vida", "la trama circular" florece con una suerte de fundamentos progresivos a cada instante.

El tercero y último intelectual que entrelazamos con el pensamiento capriano, obedece al filósofo y sinólogo Francois Julien, quien plantea hábilmente la 
antigua vía de la sabiduría, abriendo posibilidades distintas al pensamiento que ha desarrollado la filosofía para comprender el mundo. El autor vuelve a las reflexiones antiquísimas de la cultura China, tomando de Confucio la idea de comprender que "un sabio no tiene ideas", en el sentido de no atarse a ninguna de ellas, debido al distanciamiento que aquello genera con los fenómenos de la vida y que compromete con conceptos, fijaciones con la parcialidad, la codificación insulsa y la privación de la disponibilidad. Entendiendo esta última, como la oportunidad para conocer múltiples realidades sin caer en cerraduras que imposibiliten permanecer con la mente abierta, con el deseo de aprehender la realidad para tomar consciencia del fondo que dispensa lo evidente y que precisamente por tenerlo siempre en la línea inmediata de nuestra mirada, no lo vemos, o como plantea Julien, no lo alcanzamos a ver.

En general, la perspectiva de Julien consiste en abrir la razón, no en renunciar a su exigencia para procurar salir de un pensamiento occidental lineal y poder entrar en un pensamiento oriental circular. Pues Julien citando a Wittgenstein (2001), se emparenta al pensamiento de este último al referir: «La idea ya está agotada, ya no vale para nada [...] Es como el papel de plata, que ya no puede alisarse una vez que ha sido arrugado» (p. 4). Lo que conectaría con la idea de Julien, al decir que el sabio no deja de tener todo abierto porque no deja de tener todo junto.

Todo junto es lo que la teoría sistémica nos ha mostrado a partir de Capra y la urdimbre que hemos tejido con otros pensadores. Que si bien los fenómenos que abordan son del todo complejos, dilucidan la autorreferencialidad y la sistematicidad en la medida de las preguntas, las respuestas en avanzada y dirección convergente, asimismo, en la medida de las conexiones e imbricaciones en termodinámicas constantes, como se ha referido.

Ante esto, es justo indicar que los fenómenos científicos y socio-humanos, siempre será mejor observarlos desde otros lentes que contribuyan a la explicación a la que se ha llegado para así vislumbrar las "tramas circulares" o bifurcaciones múltiples sugerentes y plurales. Las mismas que en el vuelo propio deben posibilitar confrontación con enfoques, perspectivas propias y lenguajes emergentes.

Finalmente, entendemos, con todo lo referido, la necesidad de buscar los conceptos en el movimiento y no en el anclaje, con el propósito de ser conscientes de otros sujetos de conocimiento con quienes discuten los autores sus apuestas y las propias miradas. Así, quedamos confiados en que las certezas del mundo académico, social y cotidiano, deben entrar en el constante devenir del movimiento para evitar caer del vuelo, para evitar caer en cegueras metafísicas, solipsistas y endogámicas, cuando no lineales. 


\section{Hacia una mirada propositiva para enseñar y comunicar en ámbitos educativos y culturales diversos: nuevas pedagogías para la provocación y la transgresión}

El diálogo entre educación, comunicación y cultura en el marco de lo que he venido describiendo, no podría estar más cerca que de concepciones o teorías emergentes que tengan que ver con la revisión de sus fenómenos desde la incertidumbre y el movimiento, más que desde la certeza y la quietud. Lejos de creer que la educación y los procesos culturales que se comunican con ella deben ser de una vez y para siempre específicos, lo que demuestra la realidad de los entrecruces, de las interdisciplinas, de las transdisciplinas, como se ha urdido en el presente escrito, es que los fenómenos de estudio se han desbordado y la mirada ha tenido que ampliarse, cuando no proyectarse para encontrar soluciones complejas e intervenir desde múltiples variables.

Una sociedad con futuro, con posibilidades, tendrá que caminar del lado de un pensamiento holístico e incluyente. Las miradas como las hemos presentado en el acápite anterior abundan. Por fortuna, cada vez con mayores énfasis, transgresiones, avalanchas de sentidos y enfoques que desafían la linealidad y la historia como tira. Así, los nuevos procesos educativos, comunicativos y culturales en el mundo, darán cuenta en el futuro de una sociedad sostenible a la manera de Thomas Kuhn, de un hombre consciente, reflexivo, crítico, solidario en función del humanismo y la búsqueda de un conocimiento en avanzada: pluralista, híbrido. Lo que posibilitaría el dominio de las ciencias y las disciplinas, entendido desde el adecuado direccionamiento de la tecnología, sus aplicaciones y no el desborde de los objetos en contra de sujetos que, irreflexivos, cuando no confiados, no atinen cómo proceder para evitar los rebases y las amenazas de la propia tecnología volcada hacia sí mismos. La automatización, de este modo, no debe ser el camino más recomendado para la optimización de la vida científica, educativa y cotidiana; el camino tendrá que seguir ajustado a los procesos de pensamiento que por suerte aún se mantienen en medio del acelerado crecimiento tecnológico, del hombre sin tiempo para el tiempo y la deshumanización, cuando no del deterioro social.

En consecuencia, nos preguntamos: ¿cómo serían las nuevas formas de educar y comunicar para las nuevas culturas? La respuesta, a propósito de nuestra temática, es muy compleja; no obstante, apostamos a considerar que las nuevas formas de educar y comunicar en medio de la diversidad de voces, culturas y miradas que inundan las tramas de la vida y sus procederes divergentes, convergentes y ausentes, deberán tener en cuenta un nuevo modo de comprender la circularidad del mundo científico y cotidiano, a través de prácticas educativas en campos abiertos y disponibles para los contrastes y las convergencias. Esto es, un pensamiento sistémico desde el cual construir y proponer alternativas híbridas 
de enseñanza, que comprometan los contenidos disciplinares, el arte, la música, la pintura, el teatro y la misma cotidianidad, como modelo pedagógico latente en búsqueda de la consolidación y el desarrollo de categorías de pensamiento en las aulas latinoamericanas.

Este modelo pedagógico tendrá que estar imbricando las relaciones que se tejen entre la vida elemental (gustos, intereses, diferencias, estéticas) y la vida académica (contenidos repensados) del estudiante; pues si para este lo que experimenta fuera del aula es importante, la educación tendrá que tenerlo en cuenta en sus prácticas de enseñanza. Aún más, cuando el entrecruce entre la ciencia y la vida es lo que en otras aproximaciones he fundamentado para revisar la relación entre la educación y la vida. En concreto, entre la pedagogía de la vida y la vida en la pedagogía, cuyo trasfondo vivifica las discusiones antiquísimas y recientísimas sobre prácticas de enseñanza innovadoras, diferentes; como el planteamiento emergente de Varela para "conocer" deja verse: transgresor, emergente, hilado a las consideraciones caprianas y a nuestra apuesta de sentido en la cual se hallan diálogos que detonan, cuando no, provocan.

Este estado de cosas y estas relaciones, son las que cada vez toman fuerza en las representaciones socio-mentales de los estudiantes y alguna parte de los educadores diferentes y emergentes en esta nueva sociedad. Aquellos que transgreden, pervierten, provocan y despiertan nuevas emociones en los estudiantes; aquellos que entienden que entre la emoción y la razón, hallamos el efecto, la perlocución que ha sido cercenada en modelos educativos metafísicos, tradicionales y lineales.

Desde una perspectiva sistémica, diríamos que dichas alternativas aportarían al entendimiento de variaciones educativas, comunicativas y culturales, donde el intercambio de indentidades, culturas y valores sea una constante.

Una mirada integral como la presenta Capra, permite enlazar situaciones de educación y situaciones de comunicación nuevas en las que hemos venido entrando con decisión e irreverencia a pesar de cierto aire que continua denso, circulando un pensamiento metafísico y lineal. No obstante, de la rebeldía dan cuenta algunos sectores de la intelectualidad y la educación media y superior en Latinoamérica, cuyos ejes centrales — como se ha sostenido- han estado en el reclamo de la justeza, el equilibrio económico-social y la reivindicación de derechos y autonomía propios de toda educación libre.

Sin duda, pensar en las futuras generaciones, se convierte en uno de los desafíos mayores de nuestro tiempo para la consecución de un diálogo educativo, comunicativo y cultural sostenible en tanto permita que las sociedades venideras se comuniquen desde la colectividad, la solidaridad y el reconocimiento del todo universal como parte del yo subjetivo que comparte y siente cercanía con 
el Todo. Esto nos permite plantear que un pensamiento circular aprovechando los logros acumulativos del pasado, es lo que nos posibilitará el avance en la construcción de categorías de pensamiento nuevas, para una sociedad mejor educada, comunicada y culturalizada como ha sido mi propósito defenderlo aquí.

En coherencia, una mirada circular que deviene en destrucciones, construcciones, reconstrucciones y valoraciones siempre de suyo humanas, serían detonantes de un pensamiento sistémico en la educación, la comunicación y la cultura, en la consecución de miradas convergentes hacia la proposición de ontologías nuevas que posibiliten la pluralidad, la transformación, el desequilibrio, la fuga y la subjetividad, cuando no la responsabilidad con la otredad, su diferencia y el respeto por su participación cíclica en el constructo universal.

En este sentido, estos planteamientos no dejan más que pensar que las conexiones de fondo existentes con el pensamiento capriano, le posibilitan a la teoría sistémica constituirse como fundamento válido y sustentado para explicar el mundo, los fenómenos, los sucesos, los contextos y el lenguaje con el que se abordan.

Indudablemente, si entendemos que la vida no es una línea recta, estas nociones soportan la idea que he planteado sobre lo sistémico y el paso hacia una trama circular en el entendimiento del proceder educativo. De aquí que continuar hacia un propósito liberador, colectivo, holístico y diferente, constituya el camino por seguir, animado por quienes han dado qué pensar o han provocado otras vías para conocer. Y es en ellas en las que la defensa se hace cada vez más férrea, desde la acción y la concepción de mundo que ha virado, cuando no poseído nuestro pensamiento y su práctica en directa correlación.

Con todo, avistamos, incipientemente, lo que significaría consolidar una propuesta viable y aplicable para el encuentro sistémico, educativo, comunicativo y cultural en Latinoamérica. Esa nueva manera de entender la objetividad (entre paréntesis) a la luz de Maturana, como la construcción dentro de nuestras subjetividades, en búsqueda de una educación no laxa, pero sí argumentada en lo que Prigogine, hábilmente plantea desde una especie de democratización del saber: «Toda innovación conceptual demanda una justificación precisa y debe delimitar las situaciones donde permite nuevas predicciones» (1997, p. 13).

\section{Conclusión}

A lo largo de la historia se han visto los tránsitos del hombre. No obstante, después de este panorama, sostengo que han sido constante sistematicidad y circularidad. En nuestra época aún evidenciamos rasgos estéticos del barroco, del romanticismo, de la modernidad en la "posmodernidad", etc. La reflexión 
disciplinar, entonces, en las ciencias sociales y humanas, nos ha dado qué pensar. Han demostrado que los fenómenos de estudio no están por fuera del hombre y que en esa medida el objeto se subjetiviza por influjo del sujeto, de su lenguaje al abordarlo y, en especial, de sus esquemas discursivos que lo cruzan al apalabrarlo.

En consecuencia, los énfasis y las subjetividades en esta trama circular, nos han dejado que los objetos de estudio se han expandido considerablemente, se han desbordado en el conocimiento humano. Lo anterior permite ahondar en los fenómenos de estudio desde perspectivas múltiples para revisar, analizar y explicarlos con mayor amplitud holística, mayor resignificación y reconversión cultural, social y académica. Es el caso de muchas disciplinas y ciencias que han sido citadas, entre ellas la lingüística, que abrió su mundo endógeno para fusionar miradas que abonan la periferia del lenguaje, en tanto terreno exógeno en esta la trama de la vida, en este eterno retorno (Kundera) que hemos urdido, y en la que somos una pequeña hebra, pero muy significativa en ella...

Por tanto, es necesario, en acuerdo con Fritjof Capra, una nueva comprensión científica de lo socio-humano, para que sea manifiesta en todos los niveles de los sistemas vivientes: organismos, sistemas sociales y ecosistemas que permitan una mirada sistémica en el entendimiento del todo universal en el que nos encontramos adheridos como parte fundamental.

De esta forma, queda claro que los sistemas complejos constituyen el tipo de pensamiento que este mundo solicita desde las interacciones y/o metamorfosis para las posibilidades del hombre futuro a la manera de Khun. No solamente en el mundo de la ciencia y sus avatares como hemos mostrado, sino en el mundo de la vida en el que hemos sido arrojados para el despliegue de todos nuestros entrecruces que no están por fuera del propio mundo, sino en sus tramas a las que siempre volvemos para revisar, revisar de nuevo y proponer mejores procesos en la historia de la humanidad. Lo cual en consecuencia, deja entrever las implicaciones que tienen las tramas circulares para enfrentar todas las vicisitudes humanas de otras maneras, con otros paradigmas, construyendo nuevas redes de conceptos para cambiar acciones que, en todo caso, no se separan de estos.

Finalmente, sea este momento, para seguir invitando a la observación desde la otra orilla en la que se relativiza, se aceptan las diversidades y se abre mundo a los cambios culturales y políticos; esto, como implicaciones que hemos considerado bondadosas, para una Latinoamérica mejor educada, comunicada y culturalizada en la diferencia, el respeto y la tolerancia; alejada de líneas en la trama de la vida que ya han sido bifurcadas, que ya no obligan.... 
educativo: del paradigma lineal a la trama circular

\section{REFERENCIAS}

Bühler, K. (1934). Teoría del lenguaje. Marías, J. (Trad). Madrid: Revista de Occidente.

Castro, V. H. (2005). Aprendiendo a convivir. Reflexiones filosóficas en torno a la convivencia y amistad. San Juan, Argentina: Fundación de la Universidad de San Juan.

Capra, F. (1998). La trama de la vida. Una nueva perspectiva de los sistemas vivos. Barcelona: Anagrama.

De Noguera, A. P. (2005). La dimensión ambiental en el reencantamiento del mundo de los valores sociales: una perspectiva fenomenológica. En R. Lerner \& G. Vargas (Eds.), Acta fenomenológica latinoamericana, volumen II (pp. 67-64). Bogotá: San Pablo.

García Canclini, N. (1990). Culturas híbridas. Estrategias para entrar y salir de la modernidad. México: Grijalbo.

Habermas, J. (2010). Teoría de la acción comunicativa: Complementos y estudios previos. Madrid: Trotta.

Habermas, J. (1989). El discurso filosófico de la modernidad. Madrid: Taurus.

Heidegger, M. (1974). El ser y el tiempo. México: Fondo de Cultura Económica.

Husserl, E. (2013). Ideas relativas a una fenomenología pura y a una filosofía

fenomenológica. México: Fondo de Cultura Económica.

Julien, F. (2001). Un sabio no tiene ideas. Madrid: Ediciones Siruela.

Lefevbre, H. (1972). Critica de la vida cotidiana. México: Siglo XXI.

Maldonado, C. (2005). Termodinámica y complejidad. Una introducción para las ciencias sociales y humanas. Bogotá: Universidad Externado de Colombia.

Maturana, H. (1992). La objetividad. Un argumento para obligar. España: Domen ediciones.

Morin, E. (1999). Los siete saberes necesarios para la educación del futuro. UnescoSantillana: Bogotá.

Muñiz Rodríguez, Vicente. (1992). Introducción a la Filosofía del Lenguaje II. Cuestiones Semánticas. Barcelona: Anthropos. 
Nietzsche, F. (1966). El ocaso de los ídolos. Buenos Aires: Aguilar.

Nussbaum, M. (1999). Los límites del patriotismo: identidad, pertenencia y "ciudadanía mundial". Barcelona: Paidós Ibérica.

Prigogine, I. (1997). El fin de las certidumbres. Santiago de Chile: Andrés Bello.

Ramírez Peña, L. (2007). Comunicación y Discurso. Perspectiva polifónica en los discursos literario, cotidiano y científico. Bogotá: Editorial Magisterio.

Rorty, R. (2002). Filosofía y futuro. Barcelona: Gedisa.

Serna A, J. (2007). Ontologías alternativas. Aperturas de mundo desde el giro lingüístico. Barcelona: Anthropos.

Smith, P. (2001). El caos. Madrid: Akal Ediciones.

Tobón de C, L. (1989). Las proyecciones de la Lingüística. En Forma y Función, (4), 13-22. Universidad Nacional de Colombia.

Varela, F. (1988). Conocer. Las ciencias cognitivas: tendencias y perspectivas. Cartografía de las ideas actuales. Barcelona: Gedisa.

Wittgenstein, L. (1988). Investigaciones filosóficas. Barcelona: Editorial Crítica.

\section{CIBERGRAFIA}

Glosario de filosofía (s.f.). Behaviorismo. Disponible en: http://www.webdianoia. com/glosario/display.php?action $=$ view $\&$ id $=42 \&$ from $=$ action $=\operatorname{search} \% 7 \mathrm{Cby}=\mathrm{B}$ 